
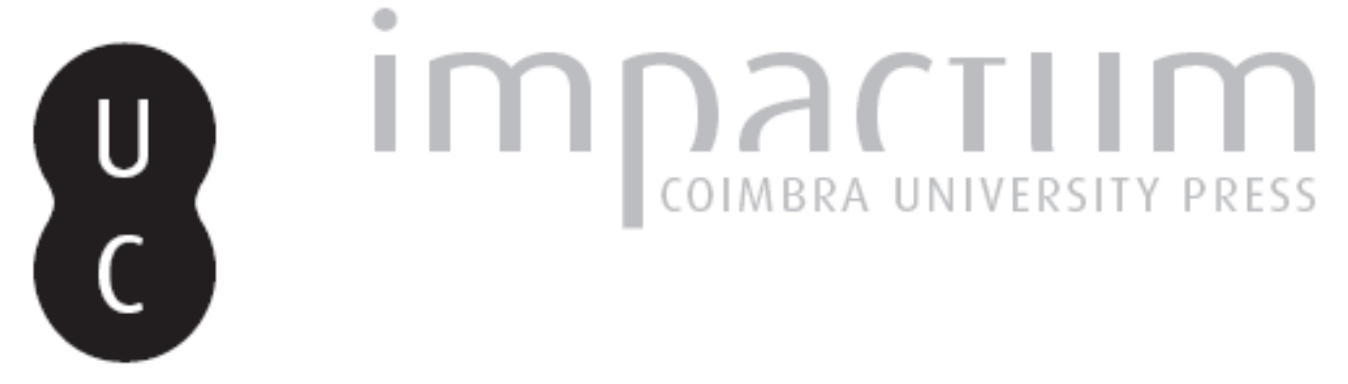

\title{
A Protecção Civil e o Ensino
}

\section{Autor(es): Rebelo, Fernando}

Publicado por: Associação Portuguesa de Riscos, Prevenção e Segurança

URL persistente:

URI:http://hdl.handle.net/10316.2/40156

DOI:

DOI:https://doi.org/10.14195/1647-7723_4_14

Accessed : $\quad$ 26-Apr-2023 10:43:35

A navegação consulta e descarregamento dos títulos inseridos nas Bibliotecas Digitais UC Digitalis, UC Pombalina e UC Impactum, pressupõem a aceitação plena e sem reservas dos Termos e Condições de Uso destas Bibliotecas Digitais, disponíveis em https://digitalis.uc.pt/pt-pt/termos.

Conforme exposto nos referidos Termos e Condições de Uso, o descarregamento de títulos de acesso restrito requer uma licença válida de autorização devendo o utilizador aceder ao(s) documento(s) a partir de um endereço de IP da instituição detentora da supramencionada licença.

Ao utilizador é apenas permitido o descarregamento para uso pessoal, pelo que o emprego do(s) título(s) descarregado(s) para outro fim, designadamente comercial, carece de autorização do respetivo autor ou editor da obra.

Na medida em que todas as obras da UC Digitalis se encontram protegidas pelo Código do Direito de Autor e Direitos Conexos e demais legislação aplicável, toda a cópia, parcial ou total, deste documento, nos casos em que é legalmente admitida, deverá conter ou fazer-se acompanhar por este aviso.

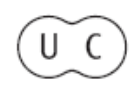




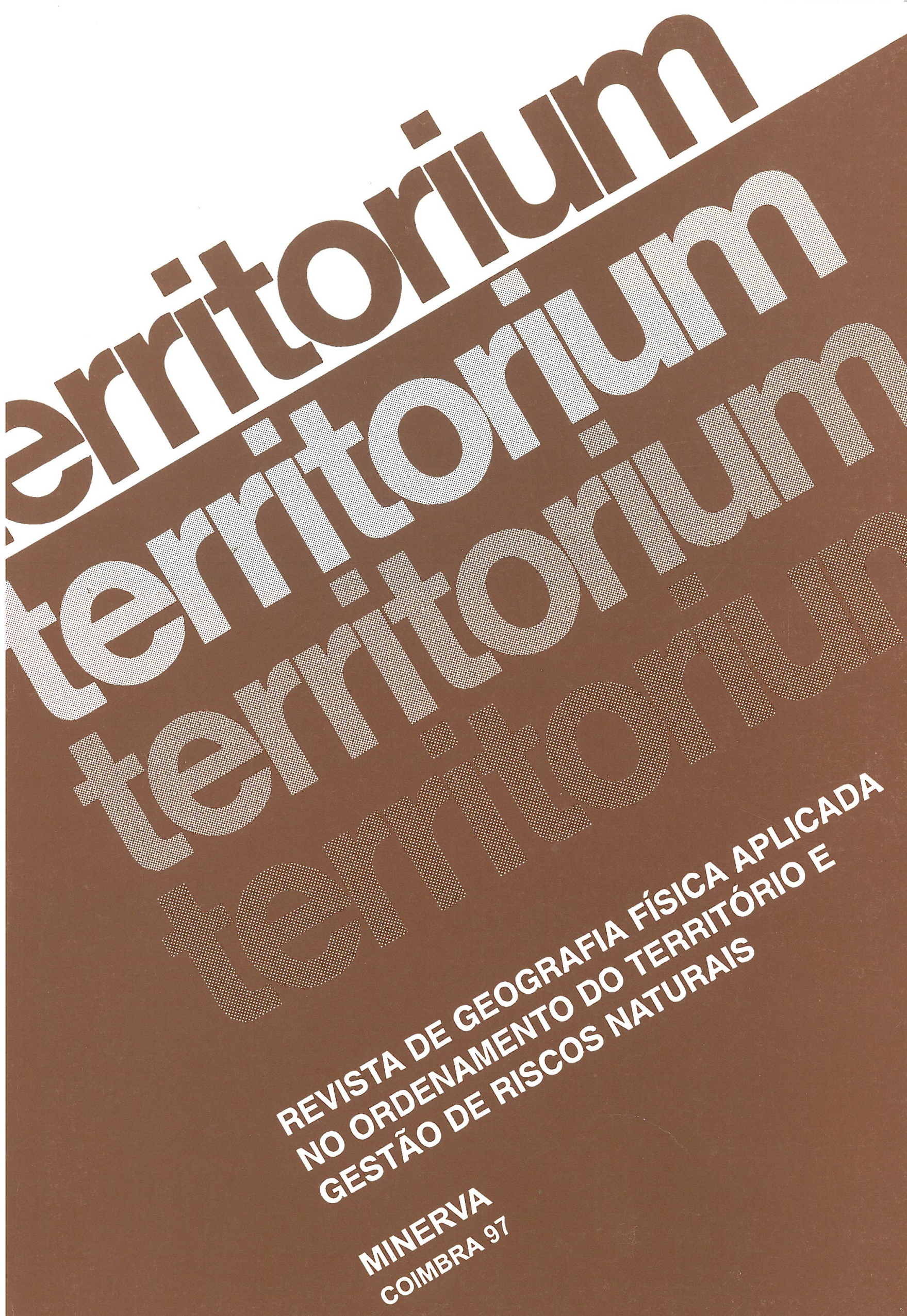


trar nesse grande país ou que num passado não muito longínquo se manifestaram no território da ex-URSS; desde sismos a alcoolismo, passando por Tchernobyl, os exemplos são abundantes e diversificados.

Os Capítulos 7e 8, respectivamente, "Vers l'explosion de la sphère financière" (CHRISTIAN PIERRET) e "Le risque nucléaire" (JACQUES ATTALI), cada um na sua especialidade, apresentam um interesse global, embora não se refiram às nossas preocupações imediatas.

Por fim, o Capítulo 9, da autoria de ANTOINE S. BAILLY, "Des sociétés qui se croyaient à l'abri" é a conclusão que se impunha para este livro sobre riscos que salienta acima de tudo os riscos naturais. E porquê? Porque, diz o Autor, "o risco natural é o menos dominado, como o ilustra esta obra: secas, inundações, tremores de terra, deslizamentos de terras, ciclones, erupções vulcânicas são ameaças conhecidas" (p. 89) e, acrescentamos nós, tantas vezes vividas nas sua manifestações catastróficas.

3. Sem serem promovidas por geógrafos, muitas outras reuniões internacionais sobre riscos se têm realizado pelo mundo. Na sua publicação periódica de carácter informativo, Risk Management, a Association de Genève vai-nos dando uma ideia disso. Entre elas, parece-nos importante destacar a que se realizou de 16 a 18 de Novembro de 1994, no Grande Anfiteatro da Sorbonne, e que foi patrocinada pelo Jornal Le Monde e pela Universidade de Paris I (Panthéon-Sorbonne). Intitulou-se CINDYNICS 94, $2 e$ Colloque International sur les Sciences du Danger.

Nas Actas deste Colóquio (Risque et Société. Paris, Presses du Louvre, 1994, 399 p.) salientam-se, antes de mais, os nomes, alguns bem conhecidos, de muitos investigadores de todas as áreas em que se pode falar de riscos. Alguns deles deixaram pequenos resumos das intervenções que fizeram, outros publicaram-nas.

Na "Editorial" (p. 2-3), PHILIPPE VESSERON, Presidente do Instituto Europeu de Cindínicas (IEC), dá um breve resumo do que foi o Colóquio em cada uma das suas cinco secções - os riscos e a sociedade, os riscos e a cidade, os riscos e a empresa, os riscos e o homem e os riscos e a cultura. Segue-se a apresentação do programa, já com a indicação dos nomes

\section{A Protecção Civil e o Ensino}

\section{Fernando Rebelo}

Educar para a Proteç̧ão Civil. Projectos para a área-escola actividades de complemento curricular é o título de um livro muito interessante assinado por ELISA VILA NOVA publicado pela Texto Editora (Lisboa, 1996, 159 p.). dos intervenientes.

Sob a designação de "os riscos e a sociedade" aparecem comunicações muito variadas. Destaquemos os resumos das de HAROUN TAZIEFF, "Les risques naturels" (p. 17-18), e de J.-Y. COUSTEAU, "La nature a horreur du risque" (p. 34). Na secção seguinte, "os riscos e a cidade", intervieram, entre outros, J.-L. DESCHANELS, "La maîtrise des risques dans la ville" (p. 52-56), C. COLLIN, "Les risques et la cité retour d'expériences" (p.58-71), LUCIENFAUGERES, "Cindynique urbaine" (p. 74-88), e IAN DOUGLAS, "Geophysical risks in the cities of SouthEast Asia" (p. 100-124). Nesta última comunicação há numerosos exemplos de manifestação de riscos naturais em áreas urbanas, tais como sismos, tsunamis, erupções vulcânicas, ciclones tropicais e inundações com eles relacionadas, mas também movimentações de terras, erosões e sedimentações, subsidências e problemas cársicos.

Na secção "os riscos e a empresa" foram apresentados muitos casos concretos de riscos tecnológicos e outros que se colocam às empresas, mas também se teorizou um pouco recorrendo a trabalhos de GEORGES-YVES KERVERN. Aliás, logo na primeira página do livro se fala de dois deles - L'Archipel $d u$ Danger (feito com PATRICK RUBISE - Paris, Economica, 1991,444 p.) e Latest Advances in Cindynics (Colloque du Management Centre Europe, Berlin, 1993).

Na secção "os riscos e o homem" houve, naturalmente, comunicações de cariz teorizante e comunicações de cariz prático, falando-se dos riscos inerentes à vida das crianças, como dos riscos de acidentes de automóvel.

Finalmente, no respeitante à secção "os riscos e a cultura" falou-se na formação inicial e na formação permanente no domínio dos riscos, no modo como fazê-la nos diferentes níveis, nas categorias profissionais a que deve primordialmente dirigir-se e na informação geral do público em matéria de riscos e de prevenção.

Risque et Société é, como vimos, um livro de Actas. No entanto, dado o tipo de matérias em causa e a maneira como algumas delas são tratadas, por vezes, parece um manual sobre riscos que pode ajudar uma vasta gama de profissionais.

Além de um Prefácio assinado pelo Gen. Cabral Couto, Presidente do Serviço Nacional de Protecção Civil (SNPC), a obra é constituida por seis capítulos e termina com "algumas informações úteis" e "referências bibliográficas". Tal como se pode ler no 
agradecimento da Autora, foi importante "a disponibilidade manifestada" pelo SNPC "na cedência de elementos para este livro, que se destina a contribuir para a difusão da mensagem da Protecção Civil na Comunidade Escolar e, através desta, na população em geral" (p. 5).

O Capítulo I, "A Protecção Civil - Espaço de Diálogo e Solidariedade" (p. 7-14), e o Capítulo II, "A Protecção Civil - uma Tarefa de Todos para Todos" (p. 15-21), têm um nítido carácter introdutório recorrendo frequentemente a citações da Lei de Bases da Protecção Civil. Mais curto ainda do que os anteriores, o Capítulo III, "Acidentes graves, Catástrofes, Calamidades" (p. 23-28) define aquilo a que em regra chamamos "crises" ou "manifestações de riscos" dando, desde logo, como exemplos de catástrofes naturais "as erupções vulcânicas, os sismos, as tempestades (ciclones, tufões, tornados...), as inundações, as secas, os incêndios devidos à queda de raios..." (p. 24). Destaquemos neste capítulo a reprodução, a cores, de uma figura a que a Autora chama "Organograma referente ao Universo da Catástrofe e respectivo ciclo, fornecido pelo SNPC" (p. 27) - embora a representação circular não pareça a ideal para se falar de um ciclo, a verdade é que lá está, a começar, a "análise de riscos", seguida da "análise de vulnerabilidades", da "minimização e prevenção", do "planeamento e preparação" (subentendendo-se este planeamento como um planeamento operacional e não como planeamento regional e urbano que deveria vir antes enquadrado na "minimização"), da "previsão e aviso", da "resposta" e, finalmente, da "recuperação". Dentro destas linhas gerais são apresentados os capítulos de pormenor, muito aprofundados e onde só temos pena de não vermos claramente escrita a palavra "geografia", pelo menos quando se refere, no quadro da "análise de riscos", a "análise científica"...

O grande Capítulo deste livro é o IV, "Principais Riscos em Portugal e Medidas de Autoprotecção" (p. 29-121). Fala-se de vulcões, de sismos, de tempestades, de inundações, de seca, de deslizamentos, de floresta e incêndios florestais, de acidentes industriais graves, de incêndios urbanos, de transporte de mercadorias perigosas e de poluição; há, para cada caso, uma introdução teórica, onde, quase sempre, se citam exemplos estrangeiros bem elucidativos, tal como indicações sobre o que se deve ou não deve fazer nesta ou naquela circunstância.

O Capítulo V, "Como Proceder em Caso de Emergência" (p. 123-133), dá algumas noções de socorrismo, enquanto o último Capítulo, o VI, "A Educação para a Protecção Civil e Autoprotecção como Componente da Educação Cívica" (p. 135-155) é um verdadeiro guia para os Professores que tenham a seu cargo o ensino destas matérias.

Curiosamente, todo o livroé ilustrado com figuras muito simples, acessíveis aos leitores mais jovens, que certamente não terão conhecimentos suficientes para entender muito do que está escrito. Grande parte do texto foi, sem dúvida, feito a pensar nos seus professores; por isso, se lamenta que as "referências bibliográficas" sejam tão poucas e tão gerais, quando sobre riscos, mesmo em Portugal, já vai havendo alguma coisa publicada.

\section{Nota sobre um Manual de Climatologia Aplicada}

\section{Nuno Ganho}

O Manualde Climatología Aplicada. Clima, medio ambiente y planificación (1995, Editorial Sintesis, Serie Mayor, $n^{\circ} 2$, colecção Espacios y Sociedades, 285p.), da autoria do Prof. Doutor Felipe Fernández Garcia, da Universidade Autónoma de Madrid é, como o autor refere na contra-capa, uma "obra dirigida a los estudiantes universitarios, a los postgraduados y a los técnicos interessados en esta materia".

O livro divide-se em 5 partes que agrupam 14 capítulos.

A $1^{\text {a }}$ parte (p. 12-59) - "Las fuentes y el método" - contém um capítulo introdutório, capítulo 1, "Clima y ambiente, clima y actividad humana" (p. 13), onde o autor contextualiza o clima no meio natural, analisa o desenvolvimento, que designa por "tardio", da climatologia como ciência, define conceitos e escalas climáticas, e integra o clima nos estudos ambientais.
O capítulo 2 - "Las fuentes de información climáticas" (p. 23) - inventaria e caracteriza as fontes de obtenção dos dados da macro e mesoclimatologia, nomeadamente as estações meteorológicas de superfície e os sensores remotos, atribuindo particular atenção à teledetecção, referindo os seus fundamentos físicos, os tipos e características dos sensores e plataformas, bem como a exemplificação das suas aplicações à climatologia.

No capítulo 3, com que termina a $1^{\text {a }}$ parte - "E1 método de estudio. Elaboración y tratamientoestadístico de los datos climáticos" (p. 35) - contempla "as técnicas estatísticas mais usuais" (p. 35) utilizadas em climatologia, que o autor agrupa em 3 grandes tipos: "1) obtenção de parâmetros de centralidade e de dispersão das séries climáticas" (p. 35) - média, moda, mediana, intervalo de variação, quantis, desvio- 